\title{
Os fatores determinantes do preço da terra agrícola no estado de Santa Catarina
}

\section{Resumo}

Nesse trabalho analisa os determinantes do preço da terra agrícola nos municípios do Estado de Santa Catarina para o período de 2006 a 2011, bem como verifica os efeitos da espacialidade sobre o comportamento do preço da terra no Estado, através da teoria da formação do preço dos ativos formulado por Keynes. A análise é feita pelo preço da terra, em Santa Catarina e as variáveis agropecuárias através da análise exploratória de dados espaciais. Com isso pela análise do I de Moran uni variado, nota-se que para os anos, de 2006 e 2011, a maioria das variáveis apresentaram I de Moran significativos. Na análise bivariada global, muitas variáveis apresentaram sinal negativo e significativo, enquanto que pela teoria deviam apresentar sinal positivo; principalmente, no ano de 2011. Isso contraria a teoria do preço da terra, e por isso outras variáveis devem influenciá-lo.

Palavras-Chave: Formação dos preços dos Ativos; Preço da terra; AEDE

Classificação JEL:C23: Q13; Q15

\begin{abstract}
This paper analyzes the determinants of agricultural land price in the municipalities of the State of Santa Catarina for the period 2006 to 2011, as well as checks the effects of spatiality on the behavior of the land price in the State, through the theory of the formation of asset price formulated by Keynes. The analysis is made by the land price in Santa Catarina and agricultural variables through the exploratory analysis of spatial data. With this the analysis of I of Moran uni varied, note that for the years of 2006 and 2011, most of the variables presented I of Moran. In bivariate analysis, many global variables showed significant negative sign, while in theory they should introduce positive sign; especially in the year 2011. This contradicts the theory of price of land, and that other variables must influence it.
\end{abstract}

Keywords: Formation of asset Price; Land Price; AEDE 


\section{INTRODUÇÃO}

No Brasil, nas décadas de 1970 a 1990, a elevação do preço da terra esteve associada ao descontrole inflacionário e era um dos fatores que causava elevação nos preços dos produtos agrícolas. Deste modo, valorizava-se, artificialmente, as potenciais receitas geradas pelo uso da terra elevando o seu valor, mesmo quando não era utilizada para fins produtivos. Após a estabilização da moeda, a partir do Plano Real, outras variáveis tornaram-se relevantes para este estudo.

A problemática da determinação ou formação dos preços da terra agrícola era, com frequência, deixada de lado por ser considerada uma preocupação exclusiva dos latifundiários. Com a atenuação do efeito inflacionário sobre o preço da terra agrícola, após o Plano Real, a partir de 1995, favoreceu significativamente as metas atingidas no processo de reforma agrária no primeiro período de governo do presidente FHC (Gasques, 2008). A partir de 1997 os programas Cédula da Terra, Banco da Terra e Crédito Fundiário incrementaram fortemente a demanda de terras e pressionaram o incremento do seu preço (Lima, 2008).

O Estado de Santa Catarina apresentou valorização média do preço das terras de 12,2\% a.a para o período de 2002 a 2010, o Estado com maior valorização da terra para o período (Plata, 2011). Há uma carência de estudos empíricos para o mercado de terras em qualquer região do país e esse fato corrobora para o estudo do mercado de terras em Santa Catarina.

Faz-se pertinente considerar que, no final da década de 2000, em um cenário de inflação controlada, ocorre uma elevação persistente dos preços da terra, e considerando as diferenças de preços entre os municípios, foi possível conduzir ao seguinte questionamento: Quais os determinantes do preço da terra agrícola nos municípios de Santa Catarina? Acredita-se que exista dependência espacial do preço da terra e de seus determinantes. Entende-se que, na presença de dependência espacial, identificando transbordamentos espaciais e formação de clusters, essa heterogeneidade espacial deve ser incorporada em um estudo sobre o preço da terra agrícola.

Assim, o presente artigo tem por objetivo principal analisar os determinantes do preço da terra agrícola nos municípios do Estado de Santa Catarina para o período de 2006 a 2011, através de uma análise de AEDE (Análise Exploratória de Dados), bem como, verificar os efeitos da espacialidade sobre o comportamento do preço da terra no Estado, através do princípio da formação do preço dos ativos formulado por Keynes.

Assim, realiza-se a análise Global do I de Moran para verificar se o preço da terra e as demais variáveis independentes apresentam correlação espacial univariado; caso apresente a 
correlação univariado elevado, justifica-se o emprego da metodologia de econometria espacial, embora esse trabalho, somente, faça análise de AEDE. Posteriormente é feita a análise global bivariado, para identificar, quais das variáveis apresentam correlação bivariado positivo ou negativo com o preço da terra e a magnitude e a significância dessa estatística. Na análise local bivariado é analisado os mapas de clusters que podem ser decompostos em: Alto-Alto, AltoBaixo, Baixo-Alto e Baixo-Baixo; um mapa que apresente as combinações de cluster Alto-Alto e Baixo-Baixo indica a correlação positiva dos clusters que afetam, positivamente, o preço da terra; caso contrário, as combinações Alto-Baixo e Baixo-Alto, os clusters afetam negativamente o preço da terra. Nessas duas análises bivariados (global e local) apontarão as variáveis que, possivelmente, podem afetar, o preço da terra.

Nesse sentido, busca-se: verificar a presença de efeitos espaciais sobre o preço da terra e seus determinantes; determinar a influência da variável da quase renda, representada pelo Valor Bruto da Produção sobre o preço da terra agrícola; determinar a influência do custo de manutenção, representado pelo Imposto Territorial Rural, na determinação do preço da terra; determinar a influência da liquidez, representada pelo conjunto das variáveis: Financiamento, Investimento Municipal, Tipo de Solo, Monocultura do Milho na determinação do preço da terra; determinar a influência de valorização patrimonial sobre o preço da terra.

O referido artigo, portanto, está estruturada em quatro capítulos, além da introdução e da conclusão. O capítulo segundo apresenta uma revisão de literatura de escritores brasileiros referente ao preço da terra agrícola. O capítulo terceiro apresenta a metodologia da análise de AEDE aplicada, a fonte de informação e a descrição de cada variável estudada. O capítulo quarto apresenta os principais resultados deste artigo: as Análises de AEDE para as variáveis agropecuárias. Por fim, a conclusão do artigo.

\section{A DETERMINAÇÃO DO PREÇO DA TERRA}

A economia capitalista é fortemente sujeita a flutuações na renda e no emprego decorrente da instabilidade, essencialmente, do estado de confiança ou investimento e da incerteza sob o qual as decisões capitalistas de investir necessariamente são tomadas. Os agentes econômicos, ao tomarem suas decisões, observam o conjunto da economia: moeda, as instituições envolvidas no seu mercado, os próprios sinais destes mercados e suas expectativas individuais. A formação do preço de terra é explicada pela teoria keynesiana e o mercado de terras. De acordo com Reydon (1992), essa ligação deve passar por alguns pressupostos sobre análise dos ativos em geral. O pressuposto tratado pelo autor é sobre as economias, em que há 
um mercado de terras consolidado, e é "economia empresarial" pois um mercado de terra consolidado é aquele no qual há títulos de propriedades aceitos pelo conjunto dos agentes econômicos em troca de dinheiro; e têm características de economia empresarial.

Com isso, a partir dos pressupostos de Reydon (1992), os preços de demanda de um ativo abstraindo pelo período de tempo envolvidos, é dado pela seguinte equação - 1

$\mathrm{P}_{\mathrm{d}}=\mathrm{q}-\mathrm{c}+\mathrm{l}+\mathrm{a}$

Para Reydon (1992), q são as quase rendas e essas podem ser definidas como os fluxos de rendas monetárias, deduzidos os custos operacionais, esperados pela posse de um ativo; nestes incluem-se as rendas produtivas, bem de capital, ou os juros e dividendos de uma ação; no caso do ativo terra considera o atributo a, separado da quase renda. No grupo da quase renda incluem-se todos os tipos de fluxos de renda esperados pela posse do ativo previamente à sua revenda, tais como benefícios especiais concedidos pelo Estado, rendas indiretas entre outros. O valor deste atributo é bastante influenciado pela expectativa geral em relação à economia, a evolução esperada dos preços que este ativo produz e expectativas de ganhos indiretos que o ativo possa gerar.

No caso do atributo c, o custo de manutenção é o custo monetário necessário para a posse de um ativo no portfólio. Também são custos que dispõem de liquidez aqueles associados à sua manutenção podendo ser incluídos neste grupo os custos de transação do ativo, os custos para obter informação para manter o ativo em carteira, a depreciação do ativo e os custos financeiros e provisão de risco, caso o ativo seja adquirido através de financiamento.

O atributo a - apreciação ou ganho patrimonial com a revenda do ativo é um componente ligado ao preço de demanda para um ativo. Além dos demais componentes colocados nesse atributo, o agente computa os possíveis ganhos que obterá com a revenda do ativo.

Por outro lado, o atributo 1 - o prêmio de liquidez - está relacionado à liquidez do ativo e a sua capacidade de se realizar no mercado "spot", passando maior certeza em um prazo mais curto, sem que o ato de vendê-lo acarrete perdas. O prêmio de liquidez de um ativo reflete tanto as características próprias conjunturais como também a organização de um mercado secundário e as condições gerais de incerteza. Logo, a liquidez no mercado de terra decorre dos seguintes atributos: poder político, o poder econômico, ao fato de potencializar a geração de rendas por um prazo infinito e o desejo bucólico que as pessoas têm de possuir terra. Há momentos nos quais todas as terras têm seus preços elevados em função de um aumento geral da liquidez conjuntural. 
O preço da terra é determinado pela demanda. No entanto, não há distinção analítica dos processos de sua formação. Isto é se é a oferta que determina o preço ou a demanda que determina o preço para o autor ambos se dão em função das expectativas dos agentes em relação aos ganhos futuros com o ativo.

Após esboçar as condições anteriores, admite-se que a terra é um ativo líquido, e como a função de oferta é igual a de demanda por considerar os agentes ofertantes e demandantes com expectativas similares pode-se retomar a equação de retorno de ativo, estipulada por Reydon (1992), mas usados aqui, no entanto voltados para o ativo terra; logo a equação - 2 determinará o preço da terra de mercado onde q é a quase renda, c o custo de manutenção, 1 o prêmio de liquidez e 'a' valorização patrimonial do ativo.

$\mathrm{P}_{\mathrm{t}}=\mathrm{q}-\mathrm{c}+\mathrm{l}+\mathrm{a}$

Lloyd (1994) reconhece que a terra agrícola é um ativo e que seu preço é determinado pela capitalização de suas rendas futuras obtidas com sua utilização na produção de bens agropecuários e na atividade especulativa como ativo de reserva de valor.

Para Rahal (2003) a função de oferta da terra, como fator produtivo é inelástica enquanto que seus preços são muito flexíveis. Embora haja queda nos produtos agrícolas, a terra continua sendo utilizada plena e intensivamente enquanto o preço de seus produtos cai demasiadamente (graças à característica de sua função oferta inelástica), já outros fatores de produção, como adubos e defensivos, são elásticos, pois uma redução do preço do produto agrícola levará a queda na utilização do bem produtivo. A terra não possui esta última característica, logo, com a redução do preço agrícola o ajuste no mercado de terras se dá mais que proporcionalmente no preço do arrendamento.

De acordo com Plata (2001) um negócio sempre é realizado quando o comprador tem expectativas mais elevadas sobre os ganhos futuros daquela terra do que o vendedor, consequentemente, os movimentos das expectativas sobre os ganhos futuros advindos da terra e, portanto, de seus preços, são as variáveis mais importantes para compreender a dinâmica do mercado de terras. As projeções de ganhos produtivos dos proprietários da terra mudam quando se alteram as condições de mercado do produto e produtividade física da terra, ou seja, a função de produção. Uma elevação do preço do produto, devido ao aumento de renda ou mudança nas preferências dos consumidores, cria expectativas de alta nas rendas produtivas da terra. As rendas derivadas da utilização da terra são determinadas pelas atividades agropecuárias. Essa 
demanda, por sua vez, é determinada pelo preço do bem produzido, tecnologia, custos de insumos, maquinaria (capital) e outros fatores utilizados na produção.

Segundo Reydon (2007), a terra apresenta algumas características que a torna um ativo atraente como fator produtivo, garantia para o crédito e reserva de valor.

A terra como um ativo apresenta três características importantes: a) é escassa, só existe em quantias fixas e não pode ser facilmente criada; b) não é móvel e c) é durável, já que não pode ser destruída facilmente. Essas características fazem da terra um ativo atraente como fator produtivo, como garantia para o crédito e como reserva de valor. A terra, além de possuir características gerais de um ativo, ainda conta com as seguintes condições especificas: a) tem um mercado secundário constituído; e b) é economicamente escassa. Assim tanto a geração de tecnologia para a elevação do seu rendimento físico quanto medidas administrativas, por exemplo, regulação efetiva dos mercados de terras, podem alterar o grau de escassez da terra. (Reydon, 2007, p.28)

Plata (2001) ressalta que os mercados locais ou específicos de terras no Brasil são imperfeitos, pois apresentam as seguintes características: a) há desigualdades expressivas na distribuição da propriedade da terra; b) os agentes econômicos individuais podem interferir na oferta e no preço da terra; c) os agentes econômicos sem-terra a procuram e não têm condições econômicas de sustentar sua demanda; d) a terra não é um produto homogêneo, as propriedades têm extensões distintas, assim como são compostas de diferentes tipos e qualidades de solos; e) existem condições espaciais que afetam o preço. Logo entre essas características da terra o estudo dá destaque a heterogeneidade das propriedades.

Chang (2012) investiga os fatores determinantes dos preços de venda da terra agrícola no Estado de São Paulo nos períodos de 1995 a 2010. Em sua abordagem contextualiza que nesse período houve certa estabilidade da moeda brasileira e vários ciclos de preços das commodities agrícolas no mercado internacional. Para isso estabeleceu três objetivos específicos: avaliar os impactos decorrentes do mais recente ciclo de expansão canavieira sobre o mercado de terras, verificou as modificações ensejadas pelas regulamentações impostas pelo avanço da cultura canavieira e averiguo também, os impactos da expansão do reflorestamento e de outras atividades silviculturas para a geração de valor no setor agropecuário paulista avalia os impactos da urbanização sobre o preço de terras rurais e busca compreender, por meio da utilização de variáveis macroeconômicas, os impactos da especulação financeira nos mercados de terras.

\section{A ANÁLISE EXPLORATÓRIA DE DADOS ESPACIAIS}

Segundo Almeida (2012), os estudos de AEDE, os dados espaciais estão distribuídos aleatoriamente significa que os valores de uma região não dependem destes atributos nas 
regiões vizinhas. Deste modo faz-se necessário conhecer um coeficiente de auto correlação espacial, o qual descreve um conjunto de dados que está ordenado segundo uma sequência espacial. Um coeficiente de auto correlação é a razão entre a covariância dos dados pela variância. Para se construir uma das estatísticas de auto correlação espacial, conforme Almeida (2012): "São necessários três elementos, a saber, uma medida de auto covariância, uma medida de variância dos dados e uma matriz de ponderação espacial (W)". A partir do coeficiente de correlação pode se formar várias estatísticas para a análise de correlação espacial, como: estatística univariada e multivariada global e o índice de auto correlação local.

\subsection{A ESTATÍTICA UNIVARIADA E MULTIVARIADA GLOBAL}

Uma estatística univariada global é o I de Moran, em que utiliza a medida de auto covariância na forma de produto cruzado, a importância de se fazer essa estatística é devido a análise exploratória de dados e assim conhece-los. Algebricamente essa estatística é dada por:

$I=\frac{n}{S_{0}} \frac{\sum_{i} \sum_{j} w_{i j} z_{i} z_{j}}{\sum_{i=1}^{n} z_{i}^{2}}$

Ou matricialmente

$I=\frac{n}{S_{0}} \frac{z^{\prime} W z}{z^{\prime} z}$

Na equação-3, no qual "n" é o número de regiões "z" denota os valores da variável de interesse padronizada, "Wz" representa os valores médios das variáveis padronizadas nos vizinhos e $\mathrm{W}$ é a matriz de peso espacial. Um elemento desta matriz de peso é dado por $\mathrm{w}_{\mathrm{ij}}$. $\mathrm{S}_{0}$ é igual à operação a operação, pois todos os elementos da matriz espacial devem ser somados.

O I de Moran tem um valor esperado de -[1/n-1]. Pela fórmula nota-se que o valor de I de Moran é diferente de zero, mas quando temos grandes amostras esse valor aproximará de zero, logo o valor calculado de Moran deve ser estatisticamente igual o valor esperado dele para que haja o efeito da dependência espacial.

Essa estatística permite identificar a auto correlação positiva ou negativa. Segundo Fotheringham et al.(2000), a auto correlação positiva é dada pelos valores altos de uma variável tendem a se agrupar juntos em certas partes da área de estudo e valores baixos tendem a se agrupar com valores baixos em outras partes. Em outras palavras os valores altos da variável y irão se agrupar aos vizinhos da variável Wy; e para os valores baixo da variável y serão circundados por vizinhos Wy também com valores baixos. 
Por outro lado auto correlação espacial negativa significa que valores altos da variável de interesse de uma região tendem a estar rodeado por baixos valores desta mesma variável nas regiões vizinhas e/ou um baixo valor da variável de interesse da região tende a estar rodeado por altos valores desta variável de interesse em regiões vizinhas.

O I de Moran multivariado é uma medida de auto correlação, que averígua num contexto bivariado calculado pelas equações 5 e 6 . O objetivo desta análise é verificar se o valor numa dada variável observado tem alguma associação linear com os valores de outra variável numa região vizinha. Para exemplificar suponhamos que o pesquisador queira analisar se o preço da terra guarda alguma associação com áreas plantadas de milho. Caso haja correlação positiva, pode-se afirmar que o preço da terra sobe em regiões que apresenta grandes áreas colhidas de milho.

$I=\frac{n}{S_{0}} \frac{z_{1}^{\prime} W z_{2}}{z_{1^{\prime}} z_{1}}$

E na forma matriz $\mathrm{W}$ for normalizada na linha, a expressão a cima transforma-se em:

$I=\frac{z_{1}^{\prime} W z_{2}}{z_{1^{\prime}} z_{1}}$

O diagrama de dispersão de Moran mostra a defasagem espacial da variável de interesse no eixo vertical e o valor da variável de interesse no eixo horizontal. Nesse diagrama as duas variáveis analisadas são padronizadas, com média zero e variância unitária. Enfim o diagrama de dispersão de Moran é somente o gráfico de dispersão da nuvem de pontos representados pelas regiões, com a declividade da reta de regressão por MQO.

Com esse diagrama é possível analisar se a correlação global é negativa ou positiva, como também diagrama fornece muitas outras informações interessantes, tais como quadrantes representando quatro tipos de associação linear espacial: Alto-Alto (AA), Baixo-Baixo (BB)Alto-Baixo (AB) e Baixo-Alto (BA).

\subsection{O ÍNDICE DE AUTO CORRELAÇÃO LOCAL}

A ausência quanto a forte presença de auto correlação global podem ocultar associações espaciais locais, como clusters ou outlies espaciais. Alguns autores propuseram algumas formas de solucionar tal problema. Anselin (1995) propôs um novo indicador capaz de capturar padrões locais de associação linear, que chamou de I de Moran local. Dessa forma, Almeida (2012) define que o I local provê indicação do grau de agrupamento dos valores similares em torno de uma determinada observação, identificando clusters espaciais, estatisticamente significantes. 
Um indicador local visa analisar localmente a associação espacial do lugar, baseada num indicador de concentração espacial. É útil quando a estatística global não consegue captar eventuais bolsões localizados de concentração espacial.

O Índice de Moran Local, proposto na literatura por Anselin (1995), faz uma decomposição do indicador global de auto correlação na contribuição local de cada observação em quatro categorias (AA,BB, $\mathrm{AB}$ e $\mathrm{BA})$. Alto-Alto (AA) significa que na região i é alta em relação a média e seu vizinho j também é alto, Baixo-Baixo (BB) indica que na região i é baixa em relação á média e seu vizinho é baixo também e assim por diante.

Nos chamados indicadores LISA "Local Indicator of Spatial Association", a estatística deverá satisfazer dois critérios:

a) A capacidade, para cada observação, de indicar clusters espaciais, significativos estatisticamente;

b) A propriedade de que o somatório dos indicadores locais, para todas as regiões, é proporcional ao indicador de auto correlação espacial global correspondente;

A vantagem de um índice ser LISA, de acordo com Almeida (2012), é que quanto maior for o índice de Moran Global, menos afetará as significâncias dos testes locais. Outra vantagem é poder captar uma associação espacial negativa, ou seja, os valores são dissimilares, e os $\mathrm{I}_{\mathrm{i}}$ são negativos. $\mathrm{O}$ coeficiente $\mathrm{I}_{\mathrm{i}}$ local para uma variável padronizada pode ser expresso pelas equações 7 e 8 .

$I_{i}=z_{i} \sum_{j=1}^{j} w_{i j} z_{j}$

ou por:

$I_{i}=\frac{\left(y_{i}-\bar{y}\right) \sum_{j} w_{i j}\left(y_{j}-\bar{y}\right)}{\sum_{i}\left(y_{i}-\bar{y}\right) / n}$

Onde $\mathrm{z}_{\mathrm{i}}$ é a variável estudada na forma padronizada na região em que se deseja saber o $\mathrm{I}_{\mathrm{i}}$, $\mathrm{W}_{\mathrm{ij}}$ é a matriz de peso e $\mathrm{z}_{\mathrm{j}}$ é o valor da variável vizinha.

Após computarmos os $I_{i}$ de Moran local deve-se verificar o seu nível de significância e plotá-los no mapa. Com isso poderá observar as regiões de clusters separadas, conforme as categorias citadas (AA, AB, BA e BB).

E por fim a auto correlação espacial local bivariada. Supõem-se duas variáveis de interesse são supostos, $\mathrm{y}_{\mathrm{i}}$ e $\mathrm{x}_{\mathrm{i}}$ e padronizando essas variáveis teremos $\mathrm{z}_{1 \mathrm{i}}$ e $\mathrm{z}_{2 \mathrm{i}}$ e a formula do I de Moran local será: 
$\mathrm{I}_{\mathrm{i}}^{\mathrm{z} 1, \mathrm{z2}}=\mathrm{Z}_{1 \mathrm{i}} \mathrm{WZz}_{2 \mathrm{i}}$

Com isso temos uma forma híbrida de análise ao indicar os clusters locais bivariada.

\subsection{DESCRIÇÃO DAS VARIÁVEIS}

O de preços de terras agrícolas em Santa Catarina (Pt) é um trabalho realizado anualmente no quarto trimestre de cada ano pelo Epagri-Cepa Empresa de Pesquisa Agropecuária e Extensão Rural de Santa Catarina e Centro Socioeconômico de Planejamento Agrícola até o ano de 2014, com o objetivo de conhecer a evolução dos preços das terras utilizadas na agricultura. Sendo que para esse trabalho a classe utilizada é a terra de primeira e preços mais comum, os preços mais frequentes num total de 293 observações para os anos de 2006 e 2011. Existem localidade que não tem nos dados primários (falta no banco de dados a variável independente e são 30 no total) o preço da terra para determinado municípios, para solucionar esse problema foi observado os anos mais próximos anterior e posterior que possua o dado e obtido o preço da terra para certo município por meio da interpolação linear, para a proxy de dados para tal município.

A variável investimento (INV) é dado pela divisão entre o crédito de investimento e a receita corrente; essa variável foi incorporada para captar a liquidez, sendo que o credito de investimento é fornecido pelo Ministério da Agricultura juntamente com o Banco Central e a receita corrente é dada pelo Secretaria do Tesouro Nacional. Espera-se que tenha impacto positivo sobre o preço da terra.

O crédito rural, de acordo com Ministério Agricultura (2015), ou também conhecido como financiamento total (FNT) abrange recursos destinados ao custeio, investimento ou comercialização. É elaborado pelo Banco Central do Brasil. Espera-se que tenha impacto positivo sobre o preço da terra.

O Valor Bruto da Produção Agropecuária (VBP) mostra a evolução do desempenho das lavouras temporária e permanente e da pecuária ao longo do ano que corresponde ao faturamento bruto dentro do estabelecimento. Obtida pela PAM - Pesquisa Agropecuária Municipal. E essa variável espera-se que tenha impacto positivo sobre o preço da terra agrícola

As informações sobre o ITR e a receita corrente para os municípios de Santa Catarina são obtidas na Secretaria do Tesouro Nacional e este órgão recorre a coleta de dados contábeis, por meio do Sistema de Coleta de Dados Contábeis (SISTN), mantido em parceria com a Caixa Econômica Federal, com o objetivo de consolidação das contas nacionais.

A PAM Pesquisa Agropecuária municipal do IBGE apresenta informações sobre a área plantada, área colhida, quantidade produzida, rendimento médio obtido e valor da produção dos 
produtos das culturas temporárias e permanentes, por Grandes Regiões e Unidades da Federação. Para tanto a variável de interesse nesse trabalho será área colhida e produtividade da terra.

A produtividade do milho (PRD.M) foi incluída no modelo por ser um Proxy de liquidez, pois se espera que quanto maior a produtividade do milho, maior o interesse do investidor pela terra e portanto espera-se que impacta positivamente o preço da terra. A produtividade de uma cultura indica a possibilidade de ganhos com a posse da terra. E a produtividade é dada pela quantidade de milho colhida em quilos dividido pela área plantada em ha.

A área de milho colhida (ARC.M) é dada pela divisão área plantada com milho pela área de lavoura e área pecuária em ha para cada município. A variável é uma proxy para liquidez porque espera-se que municípios nos quais haja uma maior área plantada com milho seja um atrativo para o agricultor investir na aquisição da terra, e assim espera-se que tenha impacto positivo sobre o preço da terra.

A variável tipos de solo (SOLO) é categórica, e deste modo é enumerado a qualidade do solo de 0 à 6 , aquele que tiver a maior qualidade receberá o maior número e o de menor qualidade receberá o menor número, e assim essa variável foi elaborada por Caixeta (2015), em que o autor verifica no mapa do Cepa-Epagri, as diversas classificações de solo dentro dos municípios de Santa Catarina e julga aquelas classificações que mais predomina em cada município. Entre os tipos de solos presentes em Santa Catarina pode se citar: Espodossolo, Argissolo, Neossolo, Cambissolo, Latossolo, Nitossolo.

\section{RESULTADOS}

A análise de AEDE (Análise Exploratória de Dados Espaciais) não pode ser desprezada, pois existe uma imbricação entre a heterogeneidade espacial e a dependência espacial, isto é, a heterogeneidade pode causar a dependência espacial. Por outro lado, a dependência espacial pode causar a heterogeneidade espacial. A dependência espacial é dada pela interação dos municípios com os municípios vizinhos.

A heterogeneidade espacial ocorre devido ao fato de o fenômeno espacial não apresentar estabilidade estrutural (coeficientes variáveis, variância não constante e forma funcional diferente para vários subconjuntos de dados); com essa análise é feita uma investigação preliminar da distribuição dos dados no espaço e o arranjo destas variáveis no espaço. As análises de AEDE trazem importantes contribuições no sentido de permitir tecer algumas 
considerações sobre variáveis propostas para o estudo, bem com a escolha de um modelo que capte melhor os efeitos espaciais (ANSELIN,1988).

A partir dos mapas de desvio padrão do preço da terra de Santa Catarina, fora possível identificar a formação de arranjos ou agrupamentos de municípios para os quais o preço apresenta certa similaridade. Entretanto, não é possível afirmar se tais similaridades seriam influenciadas pela proximidade locacional entre os municípios. Neste capítulo, apresentam-se os principais resultados desta dissertação: teste para a escolha da melhor matriz de peso, as análises de AEDE para as variáveis agropecuárias e os resultados da regressão dessas variáveis.

Na tabela 1, pode-se observar as diversas convenções: Rainha, Torre, para análise nos anos de 2006 e 2011. Primeiramente, verifica-se que, dentre os valores de I Moran observados, o mais baixo é 0.4890 para o ano de 2006, enquanto o valor esperado, independente da convenção, é de -0.0034. Conclui-se, com isso, que todas as convenções se distanciam, em muito da média, do valor esperado. Assim, para encontrar o melhor modelo, deve-se buscar aquela convenção que tenha o maior I de Moran tanto para o ano de 2006 quanto para 2011. Deste modo, nota-se que a convenção torre é a que apresenta maior I de Moran tanto para 2006 quanto para o ano de 2011; com valores da estatística de 0,4896 e 0,5304 respectivamente; contra os valores da configuração torre que são de 0,4890 e 0,5297. Neste trabalho, optou-se pela configuração torre, justamente por se tratar de uma matriz simétrica.

Tabela 1: Índice I de Moran preço da terra agrícola em Santa Catarina (anos de 2006 e 2011).

\begin{tabular}{l|l|l|l|l}
\hline Ano & Convenções & \multicolumn{2}{c}{ I de Moran } & \multicolumn{1}{c}{ p-valor } \\
\hline 2006 & Rainha & 0.4890 & -0.0034 & \\
& Torre & 0.4896 & -0.0034 & 0,01 \\
\hline 2011 & Rainha & 0.5297 & -0.0034 & \\
& Torre & 0.5304 & -0.0034 & 0,01
\end{tabular}

Fonte: Elaboração própria, baseado em GEODA.

Na figura 1 estão os municípios que apresentaram o preço da terra em 2011 mais elevado: Santo Amaro da Imperatriz, Biguaçu, Antônio Carlos, Palhoça, Itapema, Camboriú, Balneário Camboriú Timbó, Blumenau, Camboriú, Itapema, Canelinha, Aguas Mornas e Rancho Queimado.

Nos demais municípios que tiveram expressivo preço da terra, no extremo oeste São João Batista. A região de São Miguel do Oeste teve municípios como Descanso, São Joao Batista e na região de Chapeco, os municípios são: Campo ere, Nova Erechim, em Xanxerê município de Ipuaçu. Na região de Joinville, os municípios de Joinville, São Francisco do Sul; em Blumenau o município de Indaial; Em Itajaí os municípios de Itajaí e na região de 
Florianópolis os municípios de Governador Celso Ramos e Biguaçu. As concentrações do preço se deram nas regiões litorâneas nordeste dos municípios próximos a Blumenau até municípios próximos de Florianópolis pode ser notado a concentração a variável nessa região ao comparar o preço da terra de 2006. Outra região em que o preço da terra tornou-se elevado foi a região de São Miguel do Oeste.

Figura 1: mapa do desvio-padrão para o Preço da Terra de 2011.

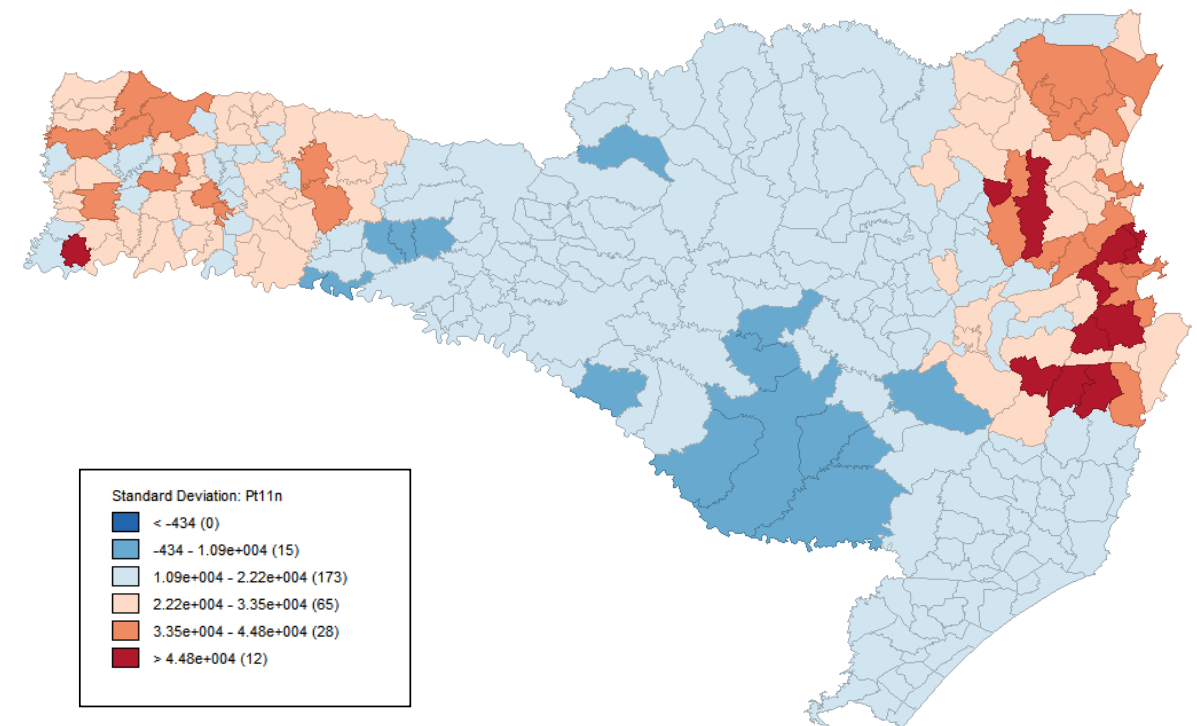

Fonte: Elaboração própria, baseado em Cepa-Epagri (2011).

\subsection{AEDE PARA AS VARÍAVEIS AgROPECUÁRIAS E O PREÇO DA TERRA AGRÍCOLA}

Os diagramas de dispersão, na figura 2, mostram os preços da terra alto em conjunto com vizinhos que apresentaram o preço da terra também alto, pois em ambos expuseram valores positivos para estatística I de Moran. Deste modo, verifica-se que a magnitude do I de Moran foi muito elevada tanto para o ano de 2006 quanto para 2011, respectivamente de 0,4896 e 0,5304, uma vez que os valores esperados para ambos eram de -0,0034. Em 2011, a estatística foi maior do que o ano de 2006. Por conseguinte, constata-se que, em 2011, o preço da terra maior para vizinhos com preços significativos foi mais evidente e houve um aumento da dependência espacial do preço da terra.

Na figura 3, tem-se os mapas de significância e de Cluster para o preço da terra nos anos de 2006 e 2011. Observa-se que os preços da terra agrícola em 2006, no Estado de Santa Catarina, estão agrupados em predominância com os clusters alto-alto e baixo-baixo, com auto correlação espacial positiva. Em 2006, verifica-se a formação de Cluster Alto-Alto no lado leste e Oeste de Santa Catarina, representados pela cor vermelha, totalizando 28 municípios, ao considerar que há uma proximidade do número dos municípios a Leste e ao Oeste, que são 
Alto-Alto. Na região central, representada pela cor em azul, há a predominância Baixo-Baixo com 48 municípios. As cidades Alto-Baixo e Baixo-Alto apresentaram um menor número totalizando apenas 6 municípios e os não significativos foram de 211.

No ano de 2011, figura 4, observa-se que a maioria dos municípios estão classificados na condição Alto-Alto e Baixo-Baixo em um total de 37 e 64, respectivamente. OS municípios Baixo-Alto são apenas 3. Com isso, verifica-se que a predominância do Alto-Alto está a Leste, representado pela cor vermelha, em uma quantia superior a de 2006. Na região Oeste, em 2011, decresceu a quantia de municípios Alto-Alto em relação a 2006. Já na região Central e Sul, houve um aumento dos municípios Baixo-Baixo, estes representados pela cor azul.

Figura 2: diagramas de dispersão de Moran univariado para o preço da terra nos municípios de Santa Catarina (anos de 2006 e 2011).
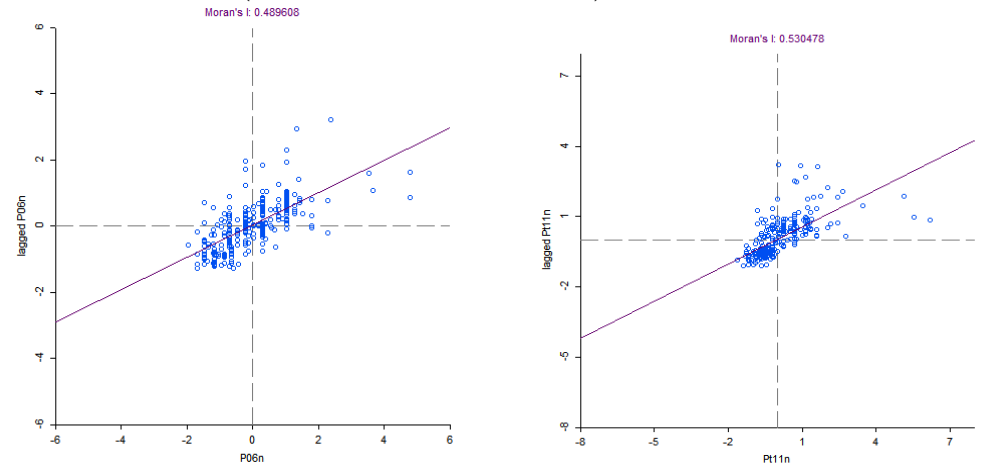

Fonte: Elaboração própria, pelo programa GEODA.

Na tabela 2, tem-se a estatística global univariada para o preço do milho que, em 2006, foi de 0,2537 . Isso indica que há predominância da produtividade de milho alta para vizinhos altos e produtividade baixa para vizinhos com produtividade baixa. No ano de 2011, essa realidade foi mais acentuada, pois o valor do I de Moran era de 0,6777. Para ambos os anos, a estatística do I de Moran é significativa a $1 \%$.

A estatística global bivariada para a produtividade do milho e preço da terra, para os anos de 2006 e 2011 , tem valores de 0,1198 e -0,2727, respectivamente. Isso indica que, em 2006, houve uma correlação positiva entre municípios com alta produtividade e vizinhos com alto preço da terra. Em ambos os anos, a estatística bivariada é significativa a 1\%. Entretanto, em 2011, essa relação se dá de forma invertida, pois há produtividade do milho alto com preço da terra baixo na vizinhança, ou vice e versa. Tal informação conduz a ideia de que o preço da terra pode estar sendo influenciado por outras atividades ou fatores que não tenham correlação com a produtividade da cultura do milho.

Os indicadores de associação espacial local, que possam ser associados as diferentes localizações de uma variável distribuída espacialmente, são usados em conjunto com o I de 
Moran; eles refinam nosso conhecimento sobre os processos que dão origem a dependência espacial, já que possibilitam encontrar "bolsões" de dependência espacial que não são evidenciados pelos índices globais. Ademais, permitem uma análise bivariada dos dados, isto é, uma variável independente pode ser testada em conjunto com a dependente. Deste modo, pode-se testar se valores altos da produtividade de milho têm valores altos do preço da terra para determinada vizinhança.

Os indicadores locais produzem um valor específico para cada objeto, permitindo, assim, a identificação de agrupamento de objetos com valores de atributos semelhante (cluster), objetos anômalos (outliers), e de mais de um regime espacial.

Figura 3: Mapa de significância e de Cluster para indicador LISA univariado preço da terra (2006).

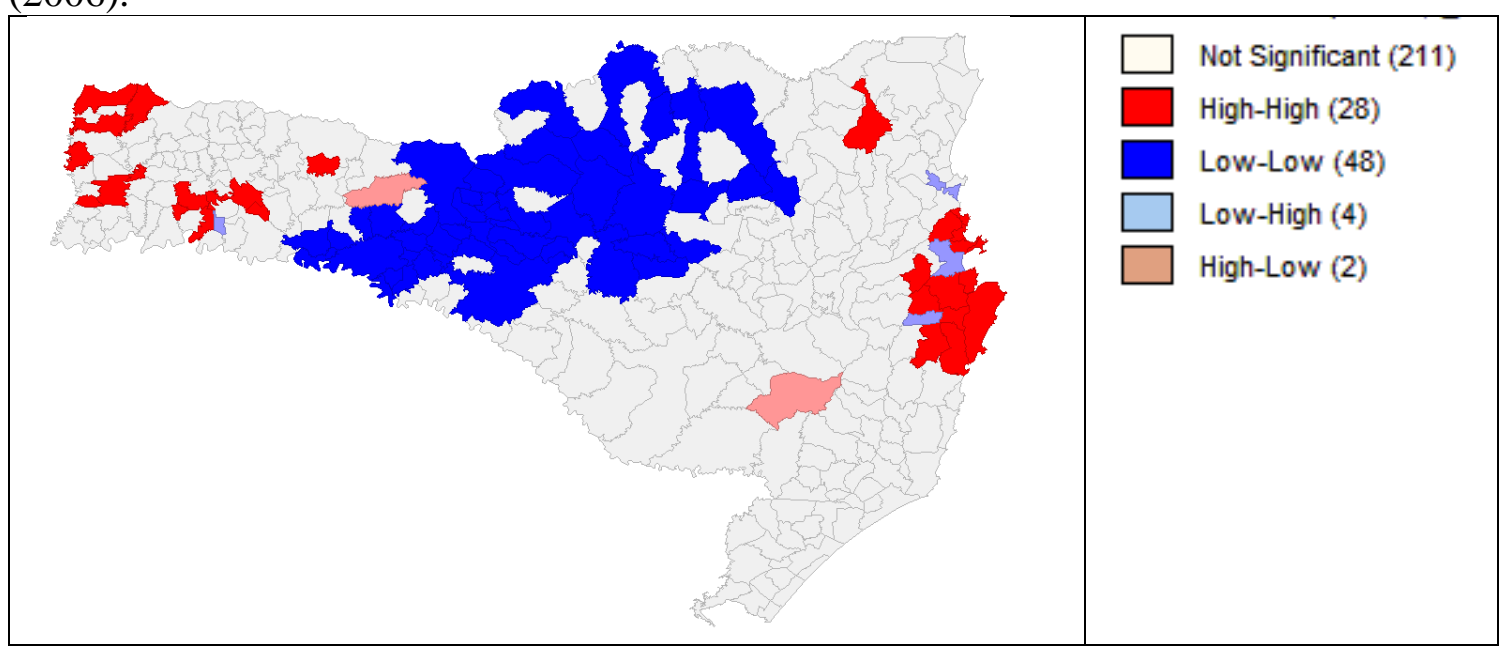

Fonte: Elaboração própria, pelo programa GEODA.

Figura 4: Mapa de significância e de cluster para indicador LISA uni variado preço da terra (2011).

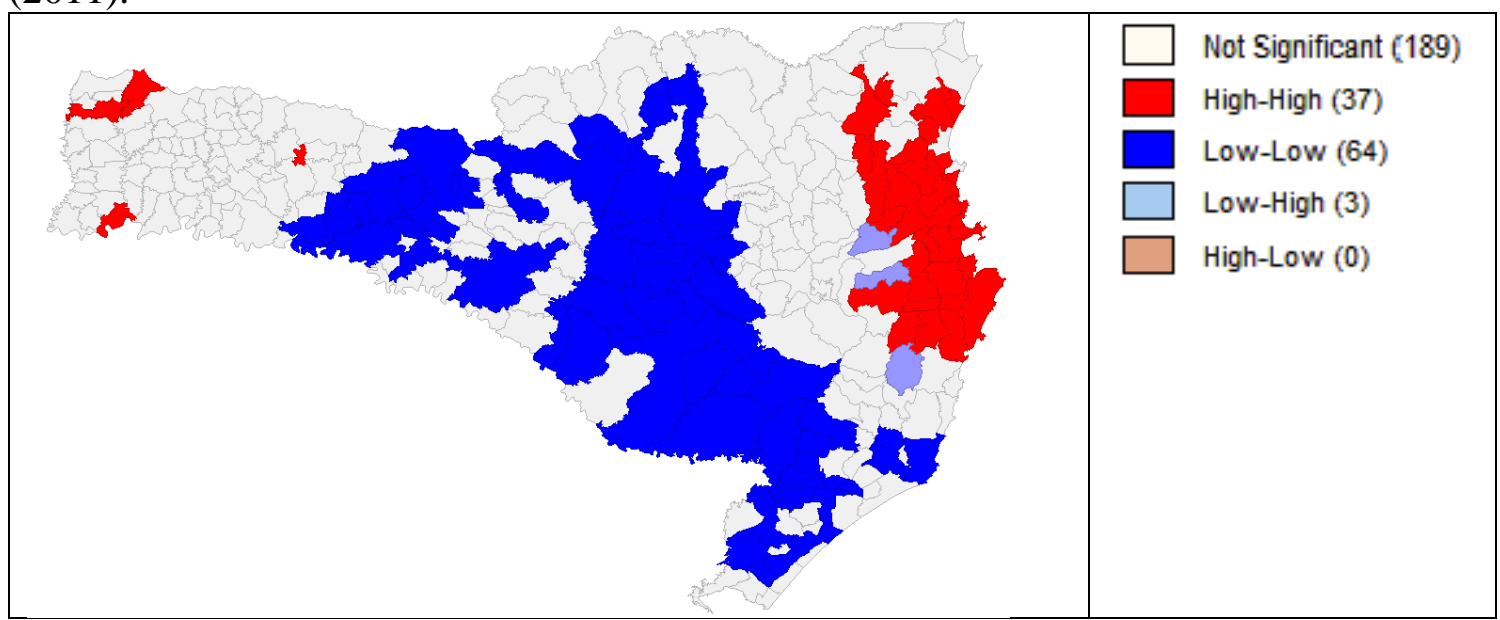

Fonte: Elaboração própria, pelo programa GEODA.

Tabela 2: Estatística I de Moran Global univariado e bivariado da Produtividade do Milho (2006 e 2011). 


\begin{tabular}{l|l|l|l|l}
\hline ANO & UNIVARIADO & P-VALOR & BIVARIADO & P-VALOR \\
\hline $\mathbf{2 0 0 6}$ & 0,2537 & 0,01 & 0,1198 & 0,01 \\
$\mathbf{2 0 1 1}$ & 0,6770 & 0,01 & $-0,2727$ & 0,01 \\
\hline
\end{tabular}

Fonte: Elaboração própria, pelo programa GEODA.

Na figura 5, em 2011, apenas 6 municípios tiveram alto-alto, sendo mais a oeste, representados pela cor vermelha, e a leste concentram 31 municípios baixo-alto pela cor azul claro na área litorânea, onde há baixa produtividade do milho com o alto preço da terra. Na área central, concentram-se Alto-Baixo em um total de 30 municípios, representados pela cor bege. Na região Sul, concentram Baixo-Baixo, com 40 municípios e 186 municípios não foram significativos para análise.

Figura 5: Mapa de significância e de Cluster para indicador LISA bivariada produtividade do milho de 2011 por preço da terra (2011).

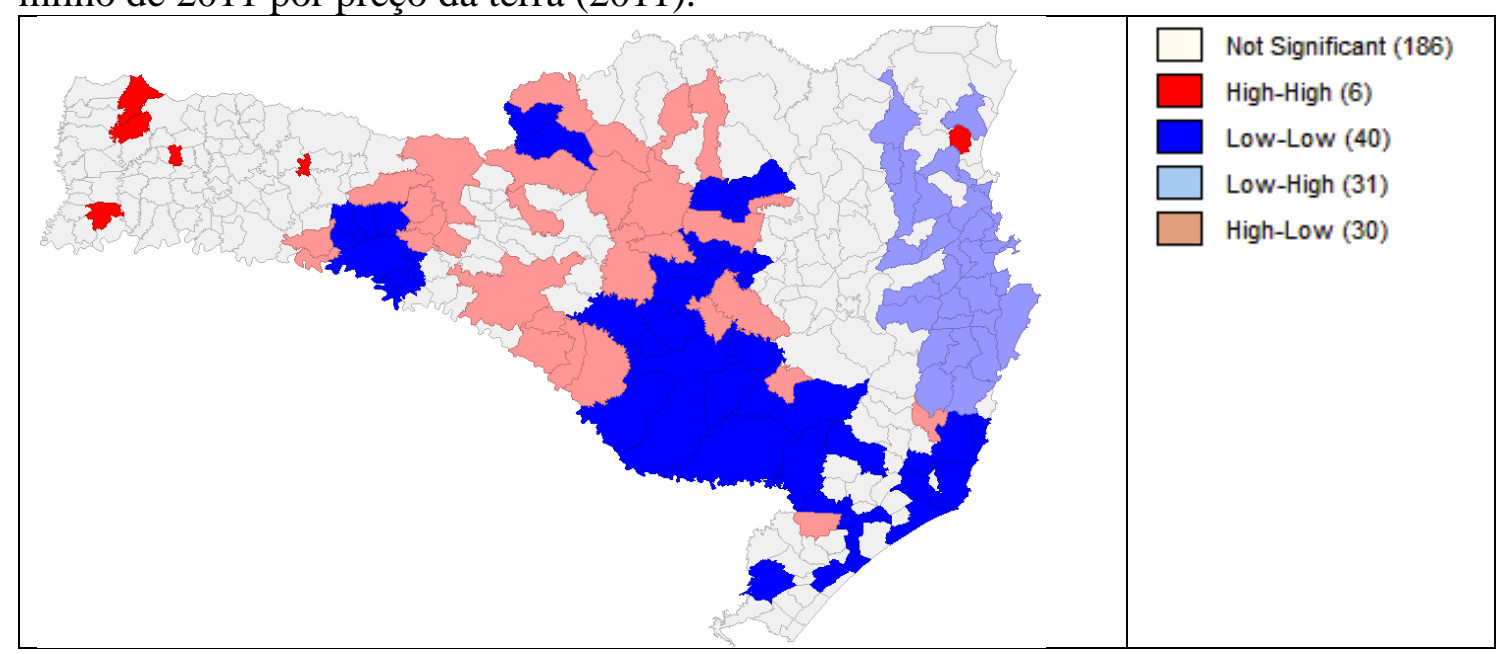

Fonte: Elaboração própria, pelo programa GEODA.

Na estatística I de Moran univariado, tabela 3, ambos os anos (2006 e 2011) apresentam valores positivos e indicam que as regiões que possuem alta área colhida do milho são vizinhas de regiões que possuem alta área colhida do milho, e vice e versa. Ao comparar o ano de 2006 com o de 2011, em que as estatísticas foram, respectivamente, de 0,0994 e 0,5021, nota-se que esse fenômeno tornou-se muito mais evidente para o ano de 2011, por apresentar o I de Moran elevado; em ambos os anos, as estatísticas são significativas a 1\%. Na estatística bivariada, os valores foram de -0,1198 e -0,1627 para 2006 e 2011, respectivamente. Com isso, tem relação negativa e, assim, regiões com maiores áreas colhidas têm o menor preço da terra. Ambos os anos são significativos a $1 \%$.

$\mathrm{Na}$ análise bivariada para o ano de 2011, figura 6, 39 municípios, a maioria, apresentam Baixo-Baixo para as regiões: Central, Sul e Litorânea Sul, representados pela cor azul. Os 25 municípios apresentam Baixo-Alto, baixa área colhida de milho com vizinhos de alto preço da 
terra, representados pela cor azul-claro. Os 23 municípios espalhados na região central apresentaram Alto-Baixo. Apenas 4 municípios apresentaram Alto-Alto, representados pela cor vermelha, e 202 não foram significativos.

Tabela 3: Estatística I de Moran Global univariado e bivariado da área colhida do Milho (2006 e 2011).

\begin{tabular}{ll|l|l|l}
\hline ANO & UNIVARIADO & P-VALOR & BIVARIADO & P-VALOR \\
\hline $\mathbf{2 0 0 6}$ & 0,0994 & 0,01 & $-0,1198$ & 0,01 \\
$\mathbf{2 0 1 1}$ & 0,5021 & 0,01 & $-0,1627$ & 0,01 \\
\hline
\end{tabular}

Fonte: Elaboração própria, pelo programa GEODA.

Na estatística I de Moran global univariado para o financiamento, tabela 4, percebe-se que, para os anos de 2006 e 2011, ambos se apresentaram muito baixos, respectivamente de 0,0003 e 0,0397. Assim, não há dependência (correlação) espacial. Em 2006 e 2011, as estatísticas não são significativas. Na análise bivariada, as estatísticas para o financiamento e o preço da terra são, respectivamente, de 0,1205 e 0,057. Com isso, pode-se dizer que, no ano de 2006, a correlação positiva entre o financiamento e o preço da terra está mais evidente do que no ano de 2011; no entanto, em 2006, o índice é significativo a 0,01; enquanto no ano de 2011 é significativo a 0,03 .

Figura 6: Mapa de significância e de Cluster para indicador LISA bivariada área colhida do milho de 2011 por preço da terra (2011).

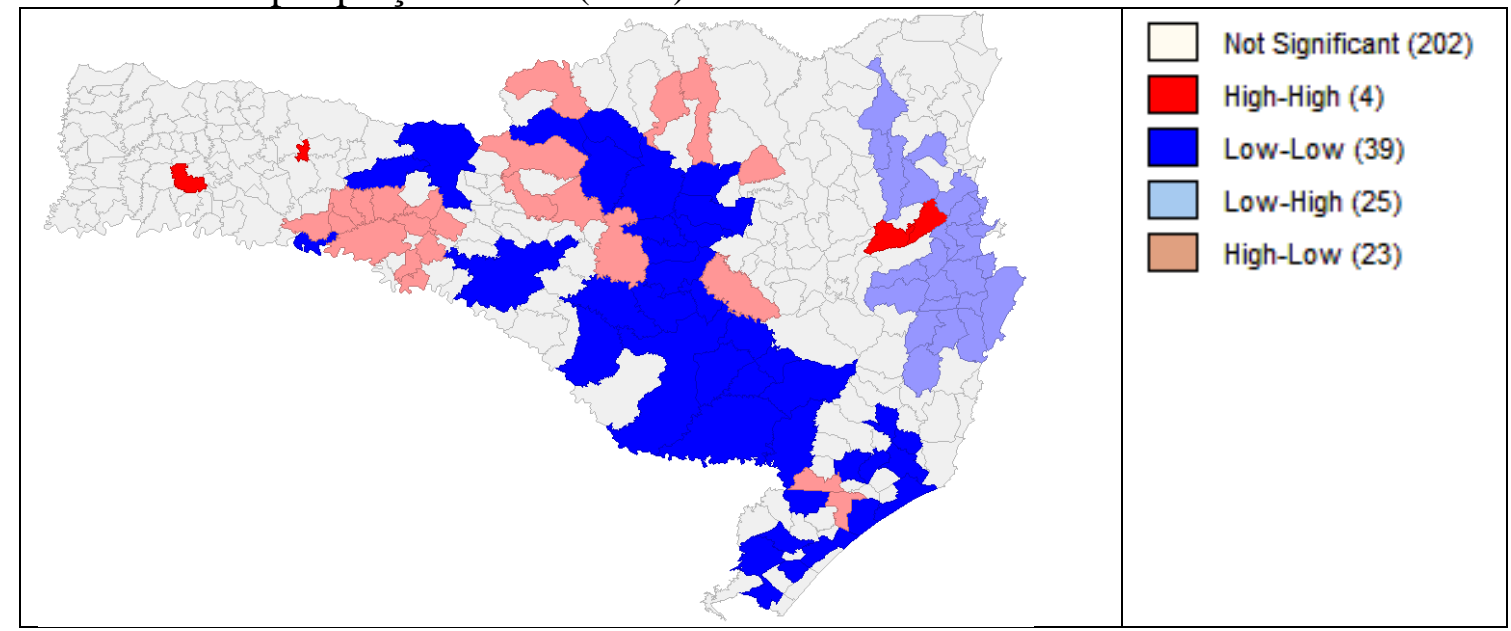

Fonte: Elaboração própria, pelo programa GEODA.

Em 2011, o mapa de cluster, dada pela figura 7, apresenta, em sua maioria, as correlações Baixo-Baixo e Baixo-Alto, e o número de municípios são, respectivamente, de 50 e 31. Isso indica que o maior preço da terra não apresenta relação com o financiamento total da produção em sua maioria. Já os Alto-Baixo e os Alto-Alto foram de 11 e 6, respectivamente. Válido expor que 195 municípios não são significativos. 
Tabela 4: Estatística I de Moran Global univariado e bivariado do financiamento total 2006 e 2011.

\begin{tabular}{l|l|l|l|l}
\hline ANO & UNIVARIADO & P-VALOR & BIVARIADO & P-VALOR \\
\hline $\mathbf{2 0 0 6}$ & 0,0003 & 0,26 & 0,1205 & 0,01 \\
$\mathbf{2 0 1 1}$ & 0,0397 & 0,11 & 0,0570 & 0,03 \\
\hline
\end{tabular}

Fonte: Elaboração própria, pelo programa GEODA.

Figura 7: Mapa de significância e de Cluster para indicador LISA bivariada financiamento total 2011 por preço da terra 2011.

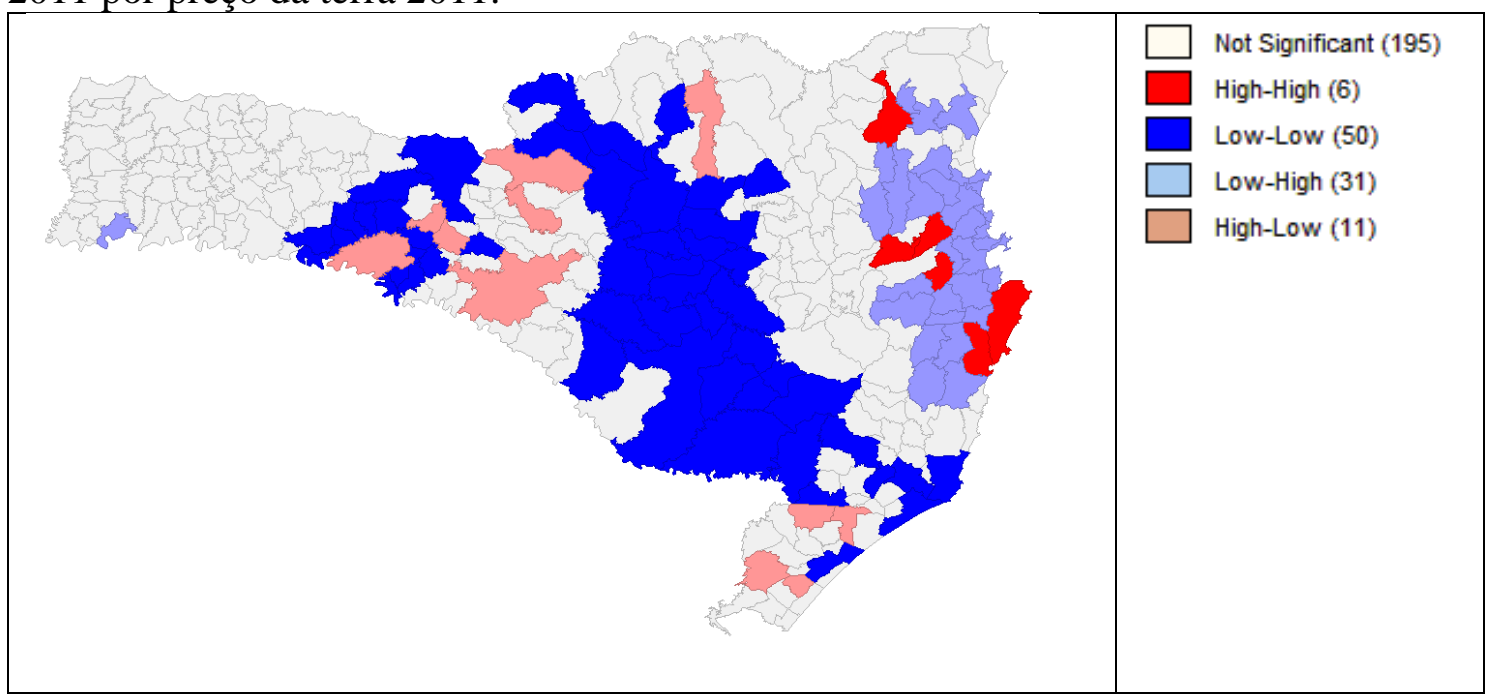

Fonte: Elaboração própria, pelo programa GEODA.

$\mathrm{Na}$ análise univariado global, o I de Moran, para o valor bruto da produção no ano de 2006, tabela 5, foi elevado a 0,2218. No ano de 2011, foi baixo: 0,0262. Esse dado aponta que, no ano de 2006, o valor da produção alto em um município também se dava no vizinho, e vise e versa. No ano de 2011, somente é significativo a 0,08, portanto, essa relação torna-se menos evidente. Em 2006, é significativo a 0,01. A análise bivariada global do valor bruto da produção e o preço da terra são, respectivamente, de -0,0231 e 0,0966. Assim, no ano de 2006 apresentou correlação negativa e, no ano de 2011, correlação positiva. Entretanto, para o ano de 2011, a magnitude da estatística foi mais significativa que em 2006, indicando que o maior preço da terra está associado a regiões com alto valor bruto da produção.

Na figura 8, há o mapa de cluster do indicador Lisa bivariado para o valor bruto da produção e o preço da terra para o ano de 2011, 44 municípios, de acordo com o mapa de cluster, apresentam Baixo-Baixo, estende-se da área central à Sul, 27 municípios a Leste apresentam Baixo-Alto, e 10 municípios, também a leste, apresentam Alto-Alto, enquanto que, 17 municípios representados pela cor bege, apresentam Alto-Baixo. Distribuídos na região norte, oeste e sul, 195 não são significativos. 
Tabela 5: Estatística I de Moran Global univariado e bivariado do valor bruto da produção e o preço da terra 2006 e 2011.

\begin{tabular}{l|l|l|l|l}
\hline ANO & UNIVARIADO & P-VALOR & BIVARIADO & P-VALOR \\
\hline $\mathbf{2 0 0 6}$ & 0,2218 & 0,01 & $-0,0231$ & 0,23 \\
$\mathbf{2 0 1 1}$ & 0,0262 & 0,08 & 0,0966 & 0,03 \\
\hline
\end{tabular}

Fonte: Elaboração própria, pelo programa GEODA.

Figura 8: Mapa de significância e de Cluster para indicador LISA bivariado valor bruto da produção 2011 por preço da terra 2011.

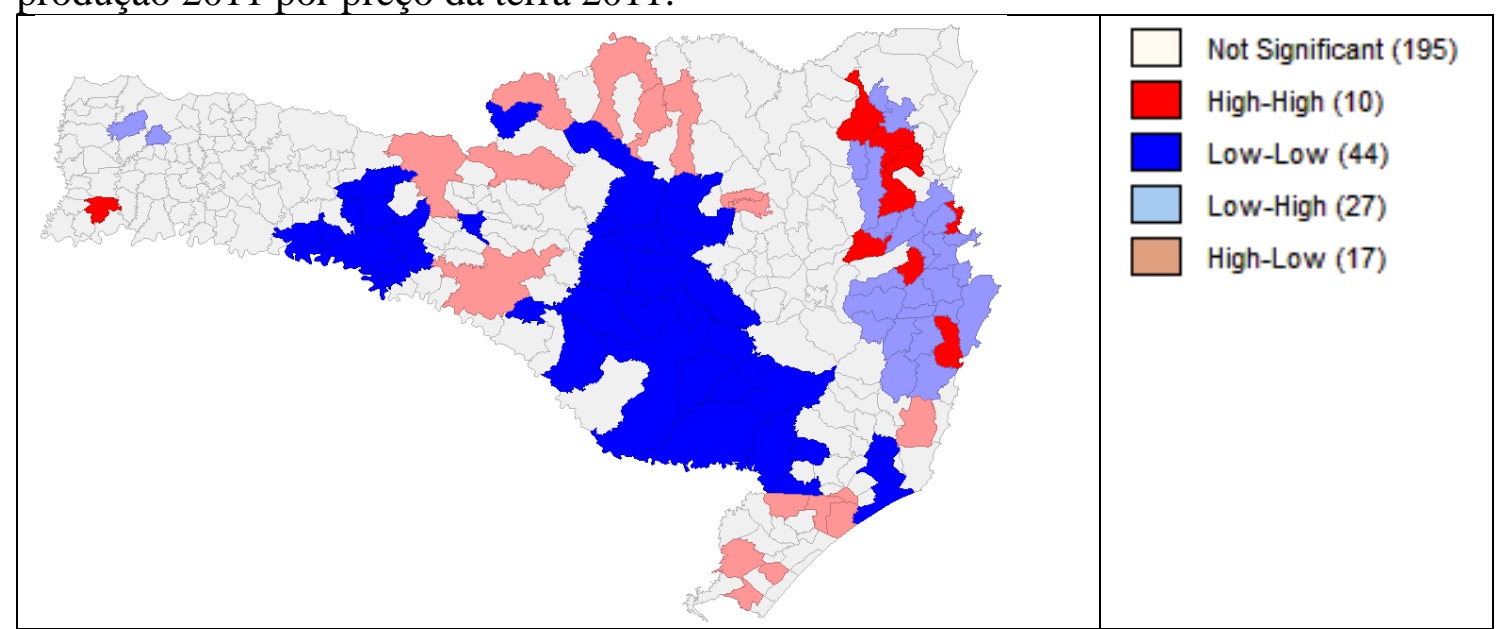

Fonte: Elaboração própria, pelo programa GEODA

$\mathrm{Na}$ análise univariado global, tabela 6, tanto para o ano de 2006 quanto para o ano de 2011, o I de Moran encontra-se bastante elevado de 0,3930 e 0,2736, ambos positivos; isso indica que os municípios onde o investimento por receita-corrente são alto, os seus vizinhos têm altos investimentos. As significâncias do I de Moran, para ambos os anos, são significativas a $1 \%$. Na análise bivariada, ambos os anos apresentam relação negativa com o preço da terra e de magnitude baixa, sendo, respectivamente, de -0,0249 e -0,0931. Somente o ano de 2011 é significativo a $1 \%$; enquanto que, em 2006, não é significativo.

No mapa de Cluster de 2011, figura 9, nota-se que a maioria dos municípios são BaixoBaixo e Baixo-Alto totalizam, respectivamente, 50 e 29. A leste concentram-se os municípios Baixo-Alto e, na região Central, Sul e oeste concentram Baixo-Baixo.

Tabela 6: Estatística I de Moran Global univariado e bivariado da relação investimento e receita corrente dos municípios e o preço da terra de 2006 e 2011.

\begin{tabular}{l|l|l|l|l}
\hline ANO & UNIVARIADO & P-VALOR & BIVARIADO & P-VALOR \\
\hline $\mathbf{2 0 0 6}$ & 0,3930 & 0,01 & $-0,0249$ & 0,17 \\
$\mathbf{2 0 1 1}$ & 0,2736 & 0,01 & $-0,0931$ & 0,01 \\
\hline
\end{tabular}

Fonte: Elaboração própria, pelo programa GEODA.

Figura 9: Mapa de significância e de Cluster para indicador LISA bivariado relação investimento e receita corrente (2011) por preço da terra (2011). 


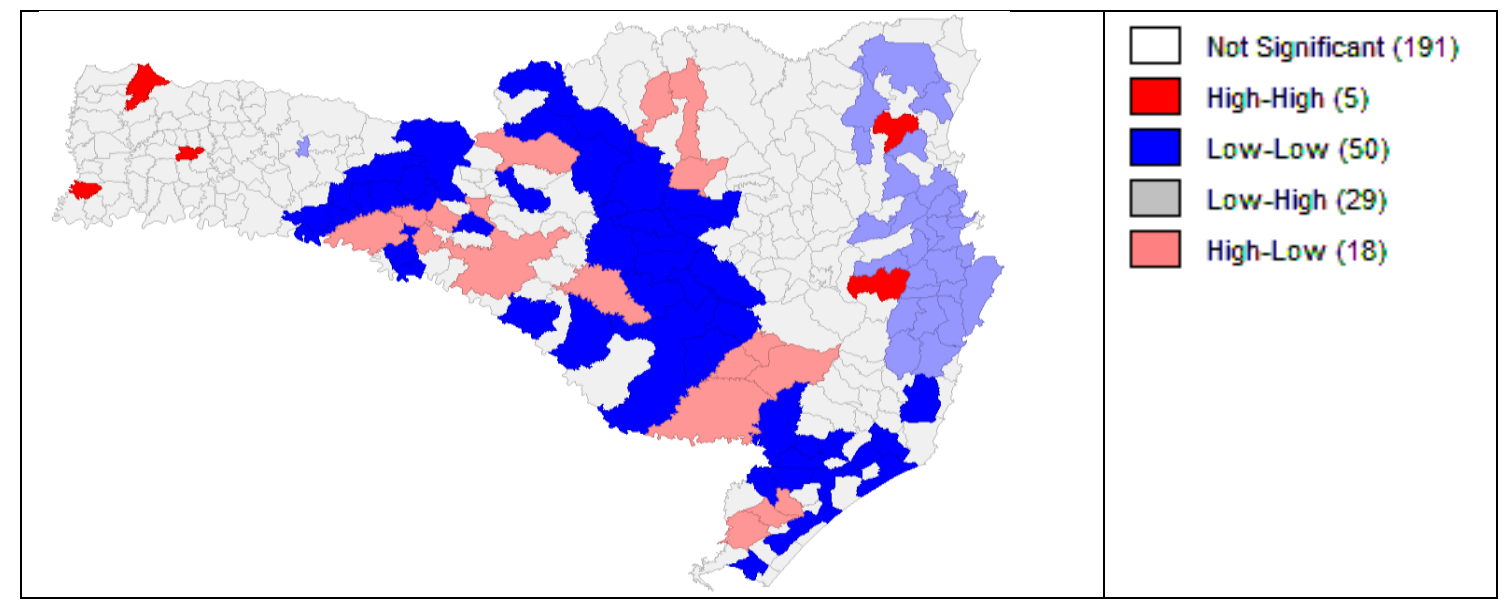

Fonte: Elaboração própria, pelo programa GEODA.

$\mathrm{Na}$ análise univariado global para a valorização patrimonial da terra, tabela 7, vê-se que os anos de 2006 e 2011 apresentam correlação positiva com suas respectivas vizinhanças e são, respectivamente, de 0,3537 e 0,1096, sendo que, no ano de 2006, essa característica torna-se mais evidente. A significância da estatística para os anos de 2006 e 2011 é de 0,01. Na análise bivariado da valorização patrimonial da terra e o preço da terra, ambas as estatísticas apresentam correlação positiva de, respectivamente, 0,1690 e 0,0973. No ano de 2006, essa característica é mais evidente e, em ambos os anos, é significativo a 0,01.

No ano de 2011, figura 42, 21 municípios são do tipo Alto-Alto, alta valorização patrimonial acompanhado de vizinhos com alto preço da terra. Esses municípios são representados pela cor vermelha, concentrados na região leste. 17 municípios são do tipo BaixoAlto e concentram-se nas regiões leste e oeste. Nas regiões Central e Sul, há concentração do tipo Baixo-Baixo com 42 municípios e 20 municípios são do tipo Alto-Baixo.

Tabela 7: Estatística I de Moran Global univariado e bivariado da valorização patrimonial da terra dos municípios e o preço da terra (2006 e 2011).

\begin{tabular}{l|l|l|l|l}
\hline ANO & UNIVARIADO & P-VALOR & BIVARIADO & P-VALOR \\
\hline $\mathbf{2 0 0 6}$ & 0,3537 & 0,01 & 0,1690 & 0,01 \\
$\mathbf{2 0 1 1}$ & 0,1096 & 0,01 & 0,0973 & 0,01 \\
\hline
\end{tabular}

Fonte: Elaboração própria, pelo programa GEODA.

Na estatística univariado global, tabela 8, para o imposto territorial rural, os anos de 2006 e 2011 são apresentados com os valores de 0,2596 e 0,1447. Em 2006, é significativo a 0,01, e, em 2011, é significativo a 0,02. Contudo, no ano de 2011, o fenômeno da correlação positiva entre municípios com impostos altos, bem como seus vizinhos terem impostos altos, faz-se menos evidente. 
$\mathrm{Na}$ análise da estatística bivariada imposto territorial rural e o preço da terra, nota-se, para o I de Moran de 2006 e 2011, os seguintes valores: de 0,1246 e 0,1522, respectivamente, em ambos os anos são significativos a 0,01 .

No mapa de cluster do imposto territorial rural e o preço da terra no ano de 2011, figura 11, é mostrado que, existem 50 municípios que são do tipo Baixo-Baixo, baixo imposto territorial rural, acompanhado de vizinhos com baixo preço da terra, representados pela cor azul. 28 municípios são do tipo Baixo-Alto, concentrados nas regiões leste e oeste.

Figura 10: Mapa de significância e de Cluster para indicador LISA bivariado valorização patrimonial dos municípios de 2011 por preço da terra 2011.

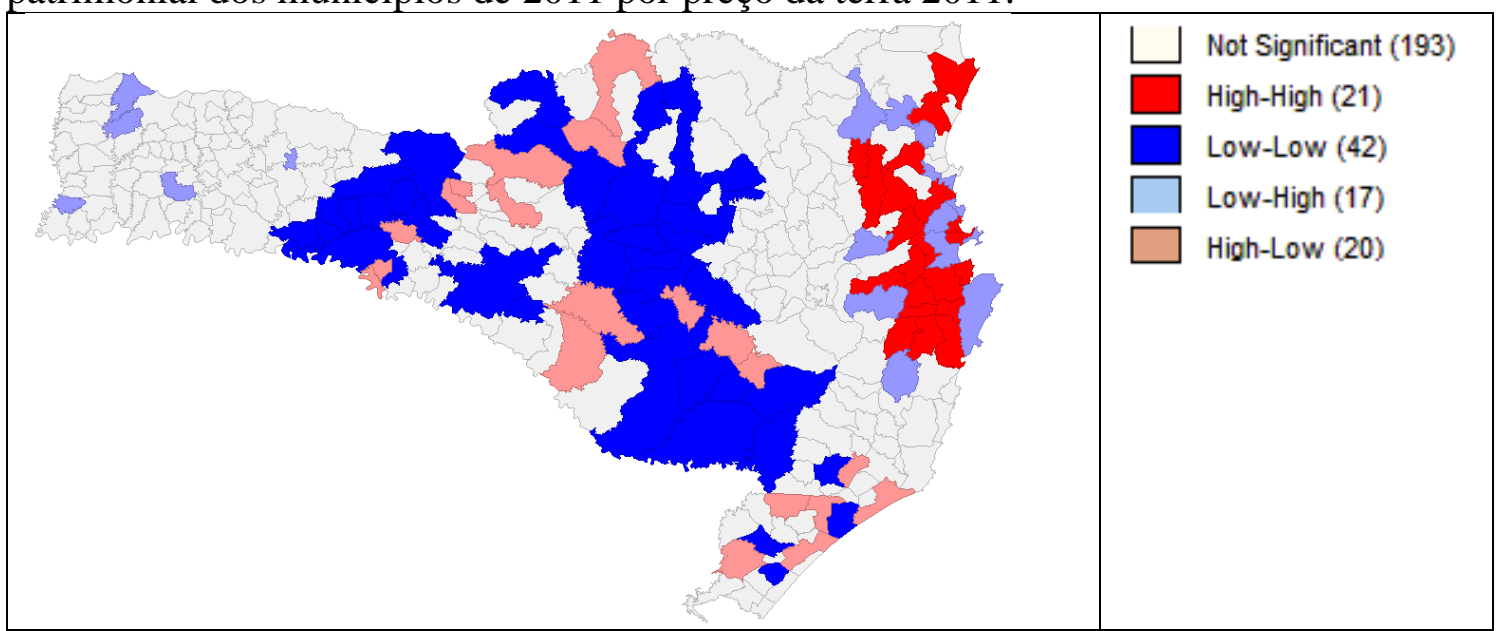

Fonte: Elaboração própria, pelo programa GEODA.

A região Central concentra o Alto-Baixo, com 14 municípios e 12 municípios são do tipo Alto-Alto. No mapa, 67 municípios são significativos a 5\% e 37 municípios são significativos a $1 \%$; enquanto 189 municípios não são significativos.

Tabela 8: Estatística I de Moran Global univariado e bivariado do imposto territorial rural dos municípios e o preço da terra (2006 e 2011).

\begin{tabular}{l|l|l|l|l}
\hline ANO & UNIVARIADO & P-VALOR & BIVARIADO & P-VALOR \\
\hline $\mathbf{2 0 0 6}$ & 0,2596 & 0,01 & 0,1246 & 0,01 \\
$\mathbf{2 0 1 1}$ & 0,1447 & 0,02 & 0,1522 & 0,01 \\
\hline
\end{tabular}

Fonte: Elaboração própria, pelo programa GEODA.

Na estatística univariado global para o tipo de solo, tabela 9, nos anos de 2006 e 2011 são apresentados com os seguintes valores: 0,5427 e 0,5427, sendo que, em 2006 e 2011, são significativos a 0,01 e apresentam alta magnitude da estática.

$\mathrm{Na}$ análise da estatística bivariada do tipo de solo e o preço da terra, notam-se os seguintes valores para o I de Moran de 2006 e 2011: de -0,1324 e -0,1210, respectivamente, sendo que, em 2006, é significativo a 0,01 e, em 2011, é significativo a 0,01; essa correlação negativa 
demonstra que terras com preços mais altos têm os tipos de solos de baixa qualidade no ano de 2006.

No mapa de cluster do tipo de solo e o preço da terra no ano de 2011 , figura 12 , a predominância é do tipo Alto-Baixo com 43 dos municípios, seguido do tipo Baixo-Baixo com 20 municípios, Baixo-Alto com 18 municípios e 15 municípios do tipo Alto-Alto. No mapa, 59 municípios apresentam significância a 5\% e 37 municípios são significativos a 1\%. 197 municípios não são significativos.

Figura 11: Mapa de significância e de Cluster para indicador LISA bivariado imposto territorial rural dos municípios de 2011 por preço da terra (2011).

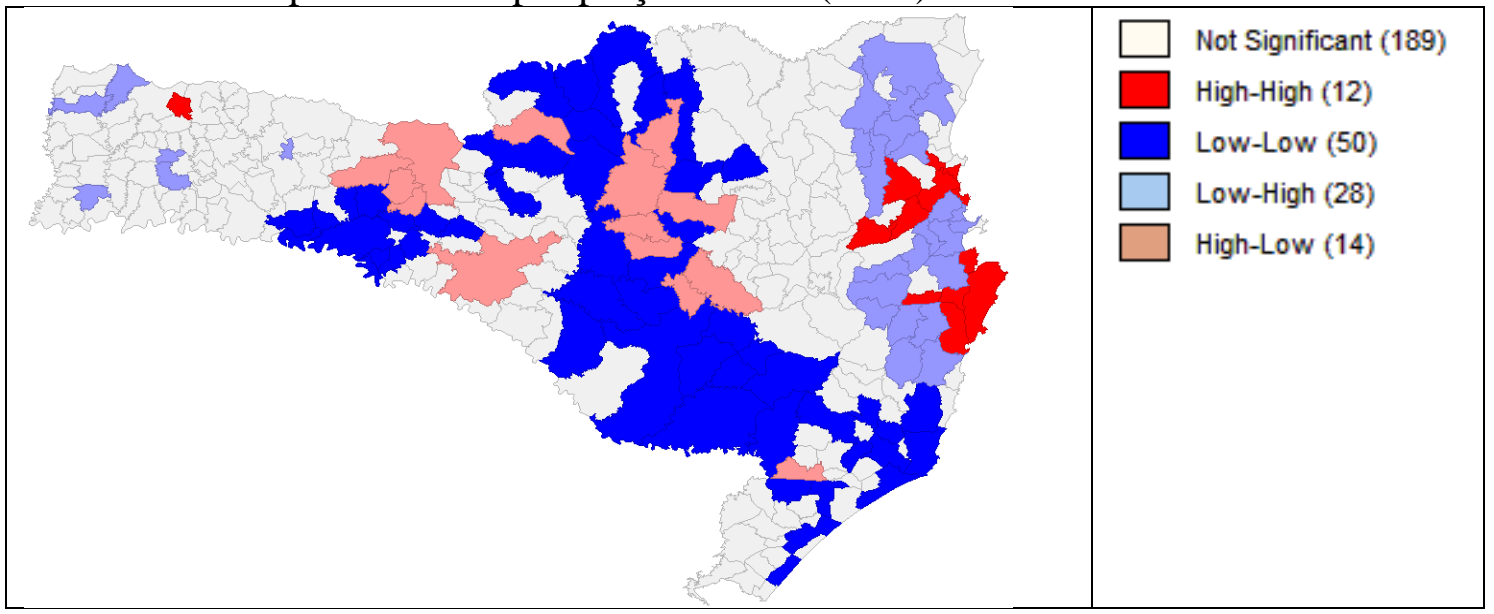

Fonte: Elaboração própria, pelo programa GEODA.

Tabela 9: Estatística I de Moran Global univariado e bivariado do tipo de solos dos municípios e o preço da terra (2006 e 2011).

\begin{tabular}{l|l|l|l|l}
\hline ANO & UNIVARIADO & P-VALOR & BIVARIADO & P-VALOR \\
\hline $\mathbf{2 0 0 6}$ & 0,5427 & 0,01 & $-0,1324$ & 0,01 \\
$\mathbf{2 0 1 1}$ & 0,5427 & 0,01 & $-0,1210$ & 0,01 \\
\hline
\end{tabular}

Fonte: Elaboração própria, pelo programa GEODA.

Figura 12: Mapa de significância e de Cluster para indicador LISA bivariado tipo de solo dos municípios de 2011 por preço da terra (2011).

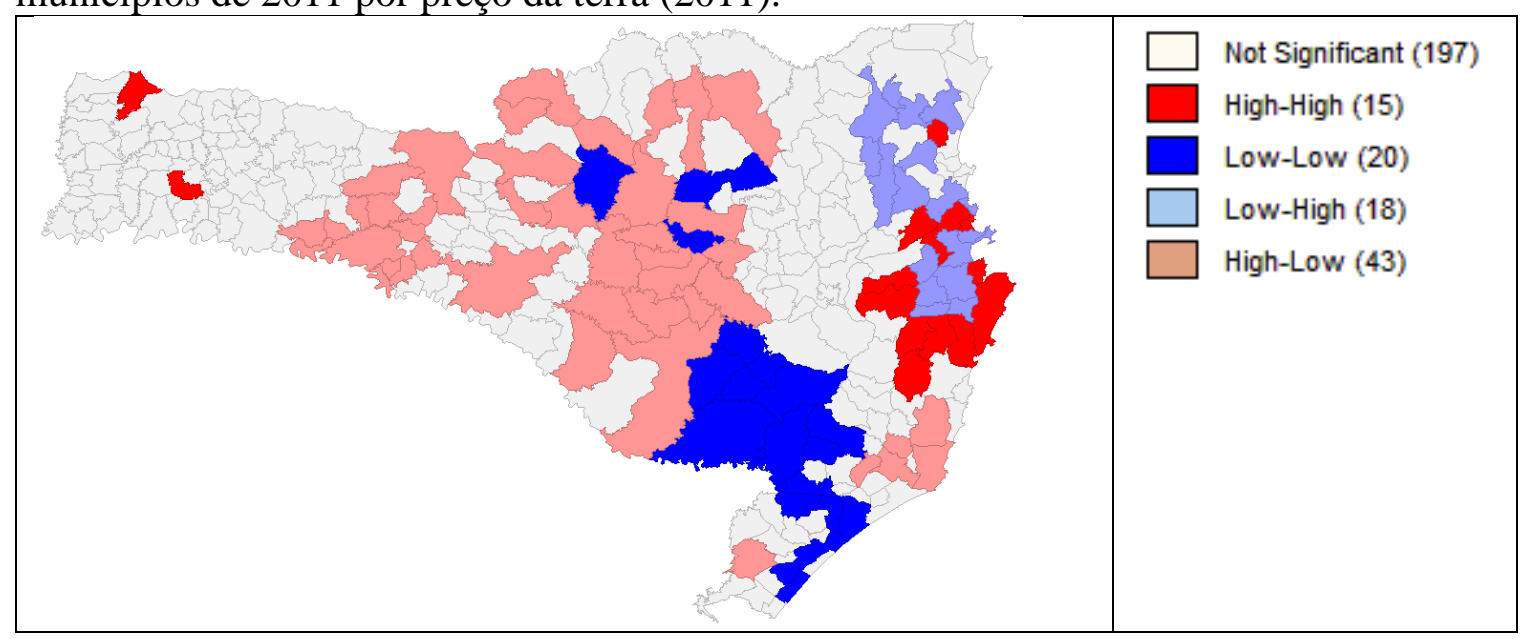


Fonte: Elaboração própria, pelo programa GEODA.

\section{CONCLUSÃO}

Foi verificado que há dependência espacial do preço da terra e de seus determinantes. A presença de dependência espacial, identifica transbordamentos espaciais e formação de clusters, essa heterogeneidade espacial foi incorporada nesse estudo sobre o preço da terra agrícola. O uso da econometria espacial é justificado pela análise do I de Moran uni variado.

A análise Global uni variado nota-se que para o ano de 2006 apenas as variáveis: financiamento total e área colhida do milho obtiveram uni variado de baixa magnitude, no entanto a área colhida do milho é significativa a 1\%, e assim como as demais variáveis é justificado o emprego da econometria espacial. Para o ano de 2011 as variáveis financiamento total e valor bruto da produção apresentaram baixos valores de I de moran uni variado e não significativa a $1 \%$. Já as demais variáveis apresentaram valores significativos para a estatística e, portanto, como a maioria das variáveis independentes e dependente tiveram o I de Moran significativos é possível o emprego da econometria espacial, por haver dependência espacial entre as observações.

Ao analisar a estatística global bivariado para o ano de 2006, nota-se que algumas variáveis foram estatisticamente significativas e positivas, como: produtividade do milho, financiamento total, valorização patrimonial e imposto territorial rural. Enquanto outras variáveis como: área colhida do milho e tipos de solo foram negativas e significativas; as demais variáveis: valor bruto da produção, investimento não foram significativas para análise.

No ano de 2011, na análise global bivariado, algumas variáveis apresentaram valores positivos e significativos para estatística, como: valorização patrimonial e imposto territorial rural; outras variáveis apresentaram o I de moran negativo e significativo, como: área colhida do milho, investimento e tipos de solo. As demais variáveis: financiamento total, valor bruto da produção não foram significativas.

Assim pela análise de AEDE, algumas variáveis estudadas podem contrariar a teoria, no entanto a confirmação dessa contrariedade se dará pela regressão. Essas variáveis são: imposto territorial rural, área colhida de milho, tipos de solo. Conclui-se que outras variáveis não agrícolas são necessárias para explicar o preço da terra agrícola em Santa Catarina.

\section{REFERÊNCIAS}

ALMEIDA, Eduardo. Econometria Espacial Aplicada. Editora Alinea, Campinas - São Paulo, 2012 . 
ANSELIN, Luc and Daniel A. Griffith, 1988, Do spatial effects really matter in regression analysis? Paper of the Regional Science Association 65, 11-34.

ANSELIN, L. Local indicators of spatial association - LISA. Geographical Analysis.v.27, n.2, p.93-115, 1995.

CAIXETA, G.M, PARRÉ, J.L., 2015. Análise Espacial do Comportamento do Preço da Terra Agrícola para o Estado de Santa Catarina. XXX - Semana do Economista da UEM.

CENSO AGROPECUÁRIO. Instituto Brasileiro de Geografia e Estatística IBGE, disponível em: http://www.ibge.gov.br/home/estatistica/economia/agropecuaria/censoagro/

CENTRO SOCIOECONÔMICO e PLANEJAMENTO AGRÍCOLA Cepa-Epagri. Secretaria de Estado da Agricultura e da Pesca Empresa de Pesquisa Agropecuária e Extensão Rural de Santa Catarina,2014. Disponível em: http://www.epagri.sc.gov.br/

CHANG, Flora L. N. C. Mudanças no uso e preço de terras do Estado de São Paulo _ período de 1995 a 2010. Piracicaba: Escola Superior de Agricultura "Luiz de Queiroz" (dissertação de mestrado), 2012.

DE LIMA, Fernando. Programa Cedula da Terra: uma releitura dos principais resultados. 2008. Tese de Doutorado. UNIVERSIDADE ESTADUAL DE CAMPINAS.

FOTHERINGHAM, A.S.;BRUNSDON, C.;CHARLTON,M. Quantitative geography: perspectives on spatial data analysis. Londres: Sage publications, 2000

GASQUES, Jose Garcia; BASTOS, Eliana Teles; VALDES, Constanza. Preços da terra no Brasil. In: 46th Congress, July 20-23, 2008, Rio Branco, Acre, Brasil. Sociedade Brasileira de Economia, Administracao e Sociologia Rural (SOBER), 2008.

LLOYD, T. Testing a Present Value Model of Agricultural Land Value. Oxford Bulletin of Economics and Statistics. 56(2), p.209-223,1994.

MALASSISE, R.L.S. O comportamento do preço da terra agrícola: Uma análise espacial para o Estado do PARANÁ. Maringá: PCE/UEM (tese de doutorado), 2014.

MINISTÉRIO DA AGRICULTURA. Política Agrícola. Crédito Rural, 2015. Disponível em:http://www.agricultura.gov.br/politica-agricola/credito-rural

MINISTÉRIO DA FAZENDA. Secretaria do tesouro nacional. Contas Anuais, 2015. Disponível em: http://www.tesouro.fazenda.gov.br/pt_PT/contas-anuais

MINISTÉRIO DA FAZENDA. Secretaria da receita federal do Brasil. Imposto sobre a propriedade territorial rural ITR Perguntas e Respostas 2011, disponível em:

http://www.receita.fazenda.gov.br/Publico/itr/2011/PerguntaseRespostasITR2011.pdf

Pesquisa Agropecuária Municipal. Instituto Brasileiro de Geografia e Estatística IBGE, disponível em: http://ibge.gov.br/home/estatistica/economia/pam/2006/default.shtm 
PLATA, Ludwig Einstein Agurto. Mercados de terras no Brasil: gênese, determinação de seus preços e políticas. 2001. Tese de Doutorado. Instituto de Economia Universidade Estadual de Campinas.

PLATA, L. E. A. et al. A dinâmica do Mercado de terras rurais e a interferência do estado nos preços. In: $49^{\circ}$ Encontro da Sociedade Brasileira de Economia, Administração e Sociologia Rural (SOBER), Belo Horizonte, 2011, Anais... Belo Horizonte: Sober, 2011.

RAHAL, C.S. A evolução dos preços da terra no estado de São Paulo: Análise de seus determinantes. Dissertação apresentada à Escola Superior de Agricultura "Luiz de Queiroz", Universidade de São Paulo, para obtenção do título de Mestre. Piracicaba, SP. 2003.

REYDON, B.P. A regulação institucional da propriedade da terra no Brasil: uma necessidade urgente. Revista de Estudos Estratégicos, Campinas, n.2, p.27-38, 2007.

REYDON. B. P. Mercado de Terras Agrícolas e Determinantes de seus Preços no Brasil: Um Estudo de Casos, 1992, p.320. Tese de doutorado. Campinas: Unicamp, 1992. 